\title{
OPTIMUM DESIGN OF 2-D REINFORCED CONCRETE FRAMES USING A GENETIC ALGORITHM
}

\author{
Masih Izadi Niaki \\ M.Sc. graduate, Dept. of Civil Engineering, Shiraz University, Shiraz, Iran \\ Mahmood Reza Maheri \\ Professor, School of Engineering, Shiraz University, Shiraz, Iran \\ Moein Bagheri \\ M.Sc. graduate, Dept. of Civil Engineering, National University of Malaysia, UKM, Malaysia \\ M.izadiniaki@gmail.com
}

\begin{abstract}
Construction of concrete structures involves at least three different materials: concrete, steel and formwork. A large number of parameters, therefore, have to be dealt with in proportioning a reinforced concrete element, including width, depth, number and diameter of rebar. Consequently, together with experience, trial and adjustment are necessary in the choice of concrete sections. A trial section has to be chosen for each critical location in a structural system. The trial section has to be analyzed to determine if its nominal resisting strength is adequate to carry out the applied factored loads. Since more than one trial is often necessary to arrive at the required section, this process is time consuming. Also, the final design of a practiced designer is different from that of a beginner and it is never known whether the result is an optimum design. The objective of this research is to design optimally reinforced concrete frames that satisfy the limitations and specifications of the American Concrete Institute (ACI) Building Code and Commentary using a Genetic Algorithm (GA). The GA used in this study has an adaptive penalty function. New options are added to the GA, including tournament selection with specified conditions or repairing operator that acts on beams and columns to accelerate convergence of the program. Design results show that the algorithm presented here compares advantageously with classic methods or other GA algorithms used previously for optimum design of concrete frames.
\end{abstract}

Keywords: concrete frame, genetic algorithm, optimization, design, reinforced concrete.

\section{INTRODUCTION}

In the design of RC frames in proportioning a reinforced concrete element, members' width and depth and the number and diameter of bars have to be dealt with. Consequently, trial and adjustment are necessary in the choice of concrete sections.

The objective of this paper is to design optimally reinforced concrete frames that comply with the limitations and specifications of the American Concrete Institute (ACI) Building Code and Commentary using a Genetic Algorithm (GA). The optimization of the reinforced concrete members is more challenging than the optimization of members made of isotropic materials, such as steel. The problem has been considered by several researchers. Krishnamoorty and Mosi (1981) presented cost optimization of two-dimensional frames with rectangular cross-sections using sequential unconstrained minimization technique (SUMT). They considered nonlinear constitutive relationships but had no actual design code. Their cost function includes only the material costs of concrete, steel reinforcement and formwork. Moharrami and Grierson (1993) carried out minimum cost design of RC building frames subjected to vertical and lateral loading, based on the ACI code ("Building" 1989) using the Optimality Criteria approach. The columns had rectangular cross-sections and the beams were considered rectangular, $\mathrm{L}$ or $\mathrm{T}$ shapes. Their design variables were the width, depth and longitudinal steel reinforcement of the beams and columns. Their cost function included the material 
costs of the concrete, reinforcement and the formwork. Fadaee and Grierson (1996) presented minimum cost design of three-dimensional RC frames with members subjected to biaxial moments and shear forces based on the ACI code ("Building" 1995). Beams and columns were assumed to have rectangular sections. The cost function included the material costs of concrete, steel and the formwork. Later, Camp, Pezeshk and Hanson (2003) discussed optimum flexural design of two-dimensional reinforced concrete frames using a genetic algorithm (GA). The frames were subjected to vertical and lateral loads and their beams and columns had rectangular sections. They applied a modified version of GA to achieve a low-cost design according to the ACI code ("Building" 1999). The design variables used were depth and width of the sections and the number and diameter of the reinforcement bars. Their cost function included the material costs of the concrete, reinforcement and the formwork. Lee and Ahn (2003) also minimized the cost of two-dimensional reinforced concrete frames subjected to gravity and lateral loading based on the ACI code ("Building" 1999) and the UBC (1997) using GA. Beams and columns had rectangular sections and their design variables were depth and width of the sections and area of the reinforcement. Their cost function included the material costs of the concrete, reinforcement and the formwork. Chan and Wang (2006) also carried out optimum nonlinear stiffness design of two-dimensional tall reinforced concrete buildings under service loads. Beams and columns had rectangular sections and area of the reinforcement was assumed as constant. The cost function also included only the concrete cost. Alqedra, Arafa and Ismail (2011) implemented GA to optimize the cost of Prestressed Concrete (PC) beams and Reinforced Concrete (RC) beams. The design variables of RC simple beams were beam width, effective beam depth, number of flexural bars and reinforcement bar diameter. Number of tendons, tendon diameter and eccentricity of the center of gravity of tendons represented the design variables of PC simple beams. The findings showed superiority of using GA technique in cost optimization over classical optimization method. Yousif and Najem (2013) applied GA for the optimum cost design of reinforced concrete continuous beams. Their variables were the dimensions and reinforcing steel and they considered the flexural, shear, and torsion effects on the beam. The produced optimum design satisfied the strength, serviceability, ductility, durability, and other constraints related to good design and detailing practice. Kaveh and Sabzi (2015) used Big Bang - Big Crunch algorithm to optimal design of reinforced concrete planar frames under the gravity and lateral loads, then they compared the results to those of GA. Beams and columns assumed to have rectangular sections.

\section{FORMULATION OF THE COST FUNCTION}

The first step in an optimization is determination of the objective function. In this research, this function includes costs of the concrete, steel and formwork for beams and columns, where formwork cost includes labor cost. Beams and columns have rectangular sections. The design variables are depth and width of the sections and number and diameter of the reinforcement bars, hence the reinforcement topology can be determined.

Description of the cost function for beams is as follows,

Minimize $F$ :

$$
F=C_{c} l_{b} b_{b} h_{b}+C_{s}\left(l_{b l} A_{s b l}+l_{b m} A_{s b m}+l_{b r} A_{s b r}\right)+C_{f} l_{b}\left(2 h_{b}+b_{b}\right)
$$

Subjected to $\quad c_{1 b} \leq 0 \quad c_{2 b} \leq 0 \ldots c_{n b} \leq 0$

Where, $C_{c}$ is cost of the concrete per cubic foot; $C_{s}$ is cost of the steel per cubic foot; $C_{f}$ is cost of the formwork per square foot (including labor); $l_{b}$ is length of the beam; $b_{b}$ is width of the beam and $h_{b}$ is height of the beam. In this research, beams are subdivided into three segments: the left segment, the middle segment and the right segment. According to this subdivision, $l_{b l}$ is length of the left segment of beam; also $A_{s b l}$ is area of the reinforcement for the left segment. Similarly $l_{b m}, l_{b r}, A_{s b m}$ and $A_{s b r}$ are length of the middle segment, length of the right segment, area of the reinforcement for the middle 
segment and area of the reinforcement for the right segment, respectively. $c_{1 b}, c_{2 b}, \ldots c_{n b}$ are beams constraint functions according to specifications and limitations of the ACI-318-05 code and commentary (ACI-318R-05).

Description of the cost function for columns is as follows,

Minimize $F$ :

$F=C_{c} l_{c} b_{c} h_{c}+C_{s} l_{c} A_{s c}+2 C_{f} l_{c}\left(h_{c}+b_{c}\right)$

Subjected to $c_{1 c} \leq 0 \quad c_{2 c} \leq 0 \ldots c_{n c} \leq 0$

Where, $l_{c}$ is length of the column; $b_{c}$ is width of the column; $h_{c}$ is height of the column and $A_{s c}$ is area of the reinforcement. $c_{1 c}, c_{2 c}, \ldots c_{n c}$ are columns constraint functions according to specifications and limitations of the ACI-318-05 code and commentary (ACI-318R-05).

\section{PENALTY FUNCTION}

All engineering optimization problems have constraints to satisfy, whereas GA is basically introduced for unconstrained optimization. To overcome this problem and optimize engineering problems with GA, we can apply penalty functions which are proposed for constrained problems to convert them into unconstrained problems. Several different ideas have been proposed to improve penalty function methods for engineering constrained optimization problems. In this research, the method introduced by Bean and Hadj-Alouane (1992) is employed. Their penalty function is revised, based on the feasibility or infeasibility of the best penalized solution during recent generations. Their penalty function allows either an increase or a decrease in the imposed penalty during evolution as shown below. This involves the selection of two constants, $\beta 1$ and $\beta 2(\beta 1>\beta 2>1)$, to adaptively update the penalty function multiplier, and the evaluation of the feasibility of the best solution over successive intervals of $N f$ generations. As the search progresses, in every $N f$ generation the penalty function multiplier is updated, based on whether the best solution was feasible during that interval. Specifically, the penalty function is,

$$
f_{p}(X, k)=f(X)+\sum_{i=1}^{m} \lambda_{k} d_{i}^{k}
$$

$$
\lambda_{k+1}\left\{\begin{array}{l}
\lambda_{1} \text { If previous } N_{f} \text { generations have infeasible best solution } \\
\lambda_{k} / \beta_{2} \text { If previous } N_{f} \text { generations have feasible best solution } \\
\beta_{1}>\beta_{2}>1
\end{array}\right.
$$

It is recommended that $\beta_{1}=5$ and $\beta_{2}=3$.

The total cost function can then be determined as, 


$$
F_{T}=F+\sum_{i=1}^{m} \lambda_{k} d_{i}^{k}
$$

After analyzing each frame, the feasibility of the frame can be assessed. If the solution is infeasible, it is penalized; otherwise the penalty term in the cost function is set at zero.

\section{RAME ELEMENTS SPECIFICATIONS Beams}

Flexural moment varies along a beam in a frame. At supports, the negative moments govern, whereas, in the middle of the beam it is the positive moment that governs. For this reason, beams are subdivided into three segments, left, middle and right as shown in Fig. 1,

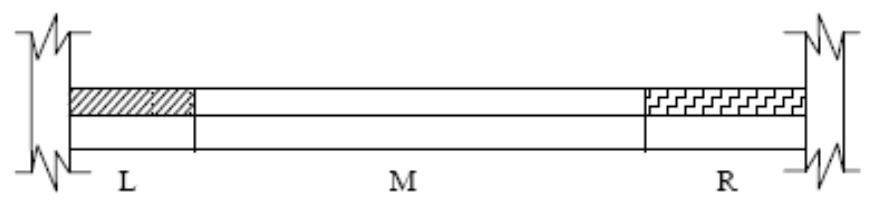

Fig. 1. Beams subdivision along their lengths.

Each segment can be designed according to its maximum moment, thereby individual longitudinal reinforcement for each segment can be found. Notice that width and depth of the section are constant along the beam.

Beams are assumed to have rectangular sections and the longitudinal reinforcements of the beams are arranged in only one layer for tensile and compression steel. Number and size of the bars in different rows are not the same but all bars in a row are of the same size. Beams section specifications are shown in Fig. 2,

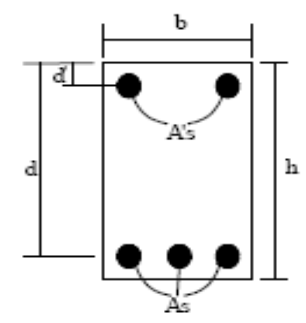

Fig. 2. Beams section specifications.

Moreover, shear reinforcement will be calculated for beams. Indeed, at first, beams dimensions and longitudinal reinforcements will be produced by GA and then the shear reinforcement will be calculated for the given specifications. GA does not produce shear reinforcement; it produces only section dimensions and number and size of the longitudinal bars. Therefore, for each beam there exist fourteen variables, two for width and depth of the section for the whole beam and four for number and size of the longitudinal bars in each segment.

\section{Columns}

Columns are considered to have a uniform section along their height. In other words, their section dimensions and number and size of the longitudinal bars are constant along their length. Similar to beams, columns have rectangular sections and their longitudinal reinforcements are arranged in only one layer for tensile and compression steel. But unlike beams, number and size of the bars in different rows are of the same size. According to the ACI, minimum number of longitudinal bars in columns is assumed to be four, two for each row. 
Production of section dimensions, number of longitudinal bars and their sizes and finally calculation of shear reinforcement is the same as that of the beams. Consequently four variables participate in columns design, two for width and height of the section and two for number and size of the longitudinal bars.

\section{REINFORCED CONCRETE FRAMES AND RELATED CONSTRAINTS}

All engineering structures have to be resistant under the applied loads. They must carry loads safely, not deform excessively. ACI-318-05 code, used in this research, outlines relations needed for design of concrete structures. These relations form constraints which are applied to beams, columns and concrete frame.

\section{Beams constraints}

1. Moment constraint: As mentioned before, flexural moment varies along the beams. Accordingly, this constraint is calculated for the left, the middle and the right segment of beams.

2. Maximum spacing for crack control: According to the Portland Cement Association (PCA) notes on ACI, the spacing of reinforcement (Grade 60 bars) closest to a surface in tension shall not exceed that given in tables 9A-1 and 9A-2 of the PCA notes on ACI.

3. Maximum deflection constraint: According to the ACI code, computed deflection of a beam, not supporting or attached to nonstructural elements likely to be damaged by large deflections, shall not exceed $l / 360^{\circ}$

4. Minimum width constraint: Minimum clear spacing between parallel bars in a layer shall be $d_{b}$, but not less than 1 inch.

5. In this research, widths of the beams are restricted to widths of their associated columns.

6. Another restriction applied to the beams is that their widths are limited to their depths.

7. Maximum depth constraint: "It is also common practice in design of reinforced concrete beams to fix the maximum ratio of the depth to the width of the beam. Typically, $h \_$max $/ b$ varies from 2 to $3 "$, [3]. In this research this ratio is set at 2.5.

8. Minimum shear reinforcement constraint: Shear reinforcement designed for specified section characteristics shall not be less than minimum shear reinforcement specified by ACI-318-05. The constraint $\mathrm{m} 8$ defined for this case is calculated for the left and the right support shear forces separately.

9. Maximum shear reinforcement constraint: Shear reinforcement must satisfy the relation below,

$V_{s} \leq 4 V_{c}$

\section{Columns constraints}

1. Minimum longitudinal reinforcement ratio constraint: Longitudinal reinforcement ratio of the columns shall not be less than 0.01 .

2. Maximum longitudinal reinforcement ratio constraint: Longitudinal reinforcement ratio of the columns shall not be greater than 0.08 .

3. Minimum width constraint: In tied reinforced compression members, clear distance between longitudinal bars shall be not less than $1.5 d_{b}$ nor less than 1.5 inches.

4. Constraint related to column interaction diagram: Columns in structural systems are rarely subjected to pure axial force; rather a combination of axial force and flexural moment is exerted to columns. This matter affects columns strength, and interaction of axial force and flexural moment has 
essential role in calculation of columns capacity. For design purpose, column load-moment strength interaction is used. If the factored axial force and bending moment lies inside the design strength diagram, the capacity of the column is satisfactory.

5. Since the frame under study is a two-dimensional frame, widths of the columns are limited to their depth.

6. Minimum shear reinforcement constraint: Shear forces are not the major criterion in columns design. Indeed columns are designed for axial force and bending moments, then they are checked for shear forces. Similar to beams, shear reinforcement of the column shall not be less than the minimum permitted shear reinforcement specified by ACI-318-05.

7. Maximum shear reinforcement constraint: Shear reinforcement must satisfy the relation below,

$V_{s} \leq 4 V_{c}$

\section{Frame constraints}

Besides beams and columns constraints, stability of the frame is considered as a whole frame constraint. If the frame is not stable laterally, the related constraint is applied to the frame.

\section{GENETIC ALGORITHM}

The genetic algorithm used in this research has an adaptive penalty function that has been already explained. The crossover operator has the probability of 0.8 , and three types of operators; one-point, two-point and uniform operators have been used. To determine which type of crossover is used, a twobit binary string is produced. The string " 00 " refers to one-point crossover, the strings " 01 " and "10" refer to two-point crossover and finally the string "11" refers to a uniform crossover. One- and twopoint crossovers are the least disruptive to the population, while uniform crossover is the most disruptive operator. The mutation rate varies between 0.008 and 0.02 . If previous generation has feasible best solution, the rate is 0.008 , otherwise the rate is 0.02 . Selection operator is a binary tournament selection with specific conditions.

Sometimes in design procedure, the designer comes across sections that violate constraints, but minor changes in section depth, section width, number of bars or diameter of bars makes it a convenient section. This problem has been dealt with adding a new operator to GA called repairing.

\section{DESIGN EXAMPLES}

\section{Uniaxial short-tied columns}

The first example is a problem presented by Zielinski et al. (1995). The aim is to design three uniaxial short-tied columns, each column is subjected to a factored axial force, $P_{f}$, and a factored bending moment, $M_{f}$. Loadings and material properties for each column is listed in Table 1.

Table 1. Design properties for short-tied columns [3].

\begin{tabular}{lccccc}
\hline $\begin{array}{l}\text { Design } \\
\text { example }\end{array}$ & $d^{\prime}$ (in.) & $f_{y}(\mathrm{psi})$ & $f_{c}^{\prime}(\mathrm{psi})$ & $P_{f}(\mathrm{lb})$ & $M_{f}(\mathrm{ft}-1 \mathrm{~b})$ \\
\hline 1 & 2.56 & 58,015 & 3,626 & 553,030 & 326,740 \\
2 & 2.76 & 58,015 & 4,351 & 400,160 & 266,997 \\
3 & 2.95 & 58,015 & 4,351 & 449,618 & 414,510 \\
\hline
\end{tabular}

Values for the column dimensions in inches range from $7 \leq b \leq 30$ and $7 \leq h \leq 30$. Camp, Pezeshk and Hanson (2003) designed this problem according to ACI-318-99, using a modified version of GA. 
In this research the designed columns have been checked by drawing their exact interaction diagrams. These diagrams show that the columns have acceptable design and their axial forces and bending moments lie inside the design diagrams. Comparison between the exact interaction diagrams and the interaction diagrams drawn in this research, shows that the latter has good accuracy. Fig. 3 shows both diagrams and the point related to loading for the first column.

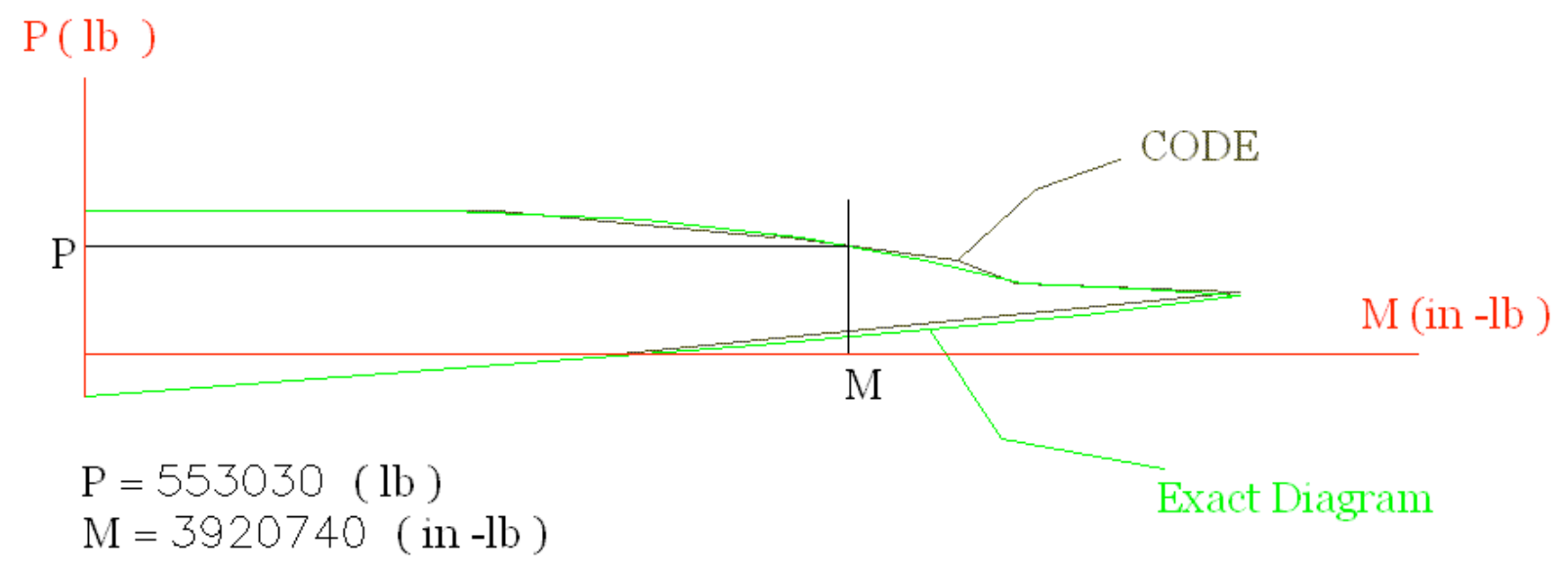

Fig. 3. First column interaction diagrams and its point of loading.

Table 2 lists the design results. It should be noted that the costs in the table are for 1 foot height of columns. Columns "Result (Ave)", "Result (Min)" and "Result (Max)" show decrease or increase percents in cost for average, minimum and maximum results attained in this research versus result attained by Camp, Pezeshk and Hanson (2003), respectively. All costs are in terms of US dollar.

\begin{tabular}{|c|c|c|c|c|c|c|c|c|c|c|c|}
\hline column 1 & $\begin{array}{c}\text { Population } \\
\text { size }\end{array}$ & $\begin{array}{l}\text { Number of } \\
\text { Generations }\end{array}$ & Ave-Cost $(\$)$ & $\operatorname{Min}-\operatorname{Cost}(\$)$ & Max-Cost $(\$)$ & Min-Size ( in ) & As ( in2) & Time (sec) & Result (Ave) & Result (Min) & Result (Max) \\
\hline $\begin{array}{c}\text { Camp, Pezeshk, } \\
\text { Hanson }\end{array}$ & - & - & - & 34.31 & - & $8.5 * 29.5$ & 4 & - & -1 & - & - \\
\hline This research & 200 & 50 & 39.81 & 39.38 & 41.12 & $13 * 30$ & 4 & $36-37$ & $16.03 \%$ & $1478 \%$ & $19.85 \%$ \\
\hline column 2 & $\begin{array}{c}\text { Population } \\
\text { size }\end{array}$ & $\begin{array}{l}\text { Number of } \\
\text { Generations }\end{array}$ & Ave-Cost (\$) & Min-Cost (\$) & $\operatorname{Max}-\operatorname{Cost}(\$)$ & Min-Size ( in ) & As $($ in2 $)$ & Time $(\mathrm{sec})$ & Result (Ave) & Result (Min) & Result (Max) \\
\hline $\begin{array}{c}\text { Camp, Pezeshk, } \\
\text { Hanson }\end{array}$ & - & - & - & 32.18 & - & $12 * 25$ & 3.14 & - & -1 & -1 & -1 \\
\hline This research & 200 & 50 & 30.98 & 30.34 & 31.68 & $9.5 * 28.5$ & 2.66 & $36-37$ & $-3.73 \%$ & $-5.72 \%$ & $1.55 \%$ \\
\hline column 3 & $\begin{array}{c}\text { Population } \\
\text { size }\end{array}$ & $\begin{array}{l}\text { Number of } \\
\text { Generations }\end{array}$ & Ave-Cost (\$) & $\operatorname{Min}-\operatorname{Cost}(\$)$ & Max-Cost $(\$)$ & Min-Size ( in ) & As ( in2) & Time ( $\mathrm{sec}$ ) & Result (Ave) & Result (Min) & Result (Max) \\
\hline $\begin{array}{c}\text { Camp, Pezeshk, } \\
\text { Hanson }\end{array}$ & - & - & - & 38.01 & - & $12 * 29.5$ & 4 & - & $=$ & - & -1 \\
\hline This research & 200 & 50 & 39.07 & 38.04 & 39.65 & $13 * 30$ & 3.6 & $36-37$ & $279 \%$ & $0.08 \%$ & $4.31 \%$ \\
\hline
\end{tabular}

Table 2. Design results for uniaxial short-tied columns.

\section{Two-Bay six-story frame}

Fig. 4 shows a two-bay six-story reinforced concrete frame designed by Rajeev and Krishnamoorthy (1998) based on Indian Standard Code of Practice for Reinforced Concrete (IS 1978) design code. The frame was also designed by Camp, Pezeshk and Hanson (2003) based on the ACI-318-99 code using a modified version of GA. 


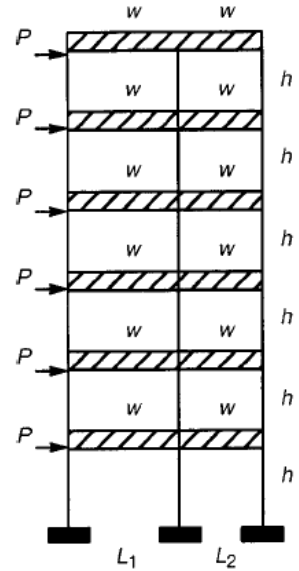

(a)

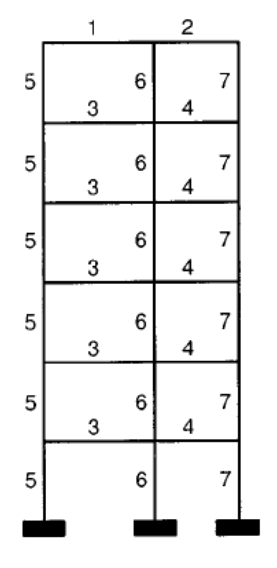

(b)

Fig. 4. Two-bay six-story frame: (a) geometry and loading; and (b) beam and column group numbering [3].

The dimensions of the frame are: $h=4 m(13.12 f t), L_{1}=6 m(19.69 f t)$, and $L_{2}=4 m(13.12 f t)$. A factored uniformly distributed vertical load of $w=30 \mathrm{KN} / \mathrm{m}(2056 \mathrm{lb} / \mathrm{ft})$ is applied to every beam in the frame. In addition, a lateral load of $P=10 K N(2248 \mathrm{lb})$ is applied to each story. The cost of concrete, steel and formwork is estimated as US\$735/ $\mathrm{m}^{2}\left(U S \$ 20.81 / \mathrm{ft}^{3}\right), U S \$ 7.1 / \mathrm{kg}\left(U S \$ 1578 / \mathrm{ft}^{3}\right)$, and US\$54/ $\mathrm{m}^{2}\left(U S \$ 5.02 / \mathrm{ft}^{2}\right)$, respectively (Rajeev and Krishnamoorthy 1998). The unit weight of concrete and steel is approximately $145\left(\mathrm{lbs} / f t^{3}\right)$ and $490\left(l b s / f t^{3}\right)$. The strength of concrete, $f_{c}^{\prime}=3000(p s i)$, and the yield strength of steel, $f_{y}=60000(p s i)$.

Rajeev and Krishnamoorthy (1998) did not consider the shear capacity of the beam sections, while Camp, Pezeshk and Hanson (2003) designed the frame with and without shear capacity of the beam. Table 3 shows design results attained by Camp, Pezeshk and Hanson (2003) when the moment and shear capacities of the beams and the load-moment interaction in the columns with moment magnification due to frame stability and column slenderness have been considered, but they did not design shear reinforcements. Also longitudinal reinforcement was considered constant along the beam.

Table 3. Design results considering column slenderness for two-bay six-story frame attained by Camp,

\begin{tabular}{|c|c|c|c|c|c|c|c|}
\hline \multirow[b]{2}{*}{$R C-G A$} & \multicolumn{4}{|c|}{ Beam Group Number } & \multicolumn{3}{|c|}{ Column Group Number } \\
\hline & 1 & 2 & 3 & 4 & 1 & 2 & 3 \\
\hline$b$ (in.) & 10 & 8 & 9 & 9 & 7 & 8 & 7 \\
\hline$h$ (in.) & 22 & 19 & 18 & 19 & 8 & 22 & 12 \\
\hline$A_{s \text { bottom }}\left(\right.$ in. $\left.^{2}\right)$ & 4 \#4 & $1 \# 5$ & 4 \#4 & $1 \# 6$ & 4 \#6 & $4 \# 6$ & $6 \# 4$ \\
\hline$A_{s \text { top }}\left(\right.$ in. $\left.{ }^{2}\right)$ & $1 \# 9$ & $3 \# 6$ & $3 \# 7$ & $2 \# 5$ & & & \\
\hline Cost & $\$ 25,471$ & & & & & & \\
\hline
\end{tabular}

Pezeshk and Hanson (2003) [3].

In this research, there are not any groupings for beams and columns. Each beam and column has its particular section, defined in the previous sections. The moment and shear capacities of the beams and columns have been considered and longitudinal and shear reinforcements have been designed for each element. Fig. 5 shows numbering of the frame elements. 


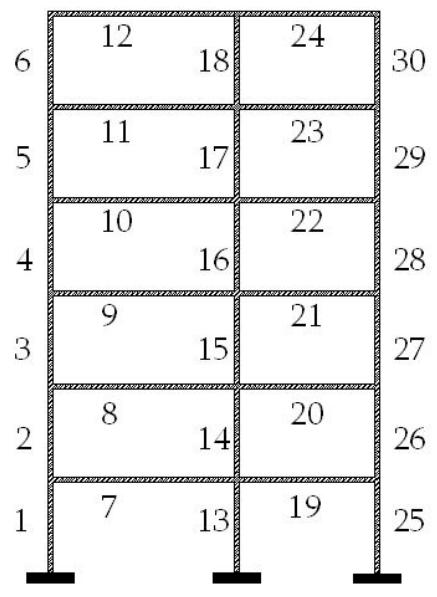

Fig. 5. Numbering of the frame elements.

This frame has 240 variables, 168 variables for beams and 72 variables for columns. Design time for 200 generations with a population size of 150 is about $80 \mathrm{~min}$. The best solution has the cost of US\$30910. Table 4 lists section dimensions, longitudinal reinforcements designed for some elements of the best solution.

In this table:

$$
\begin{aligned}
& \text { - } \quad b \text { : Width of the section, in . } \\
& \text { - } \quad h \text { : Height of the section, in . } \\
& \text { - } n b_{-} b_{-}(l / m / r) \text { : Number of bottom bars in the left } / \mathrm{mid} / \text { right segment. } \\
& \text { - } n b_{-} u_{-}(l / m / r): \text { Number of upper bars in the left } / \mathrm{mid} / \text { right segment. } \\
& \text { - } \quad n_{-} b a r \_b \_(l / m / r): \text { Bottom bars size for the left } / \mathrm{mid} / \text { right segment. } \\
& \text { - } \quad n_{-} b a r \_u \_(l / m / r): \text { Upper bars size for the left/mid/right segment. }
\end{aligned}
$$

\begin{tabular}{|c|c|c|c|c|c|c|c|c|c|c|c|c|c|c|}
\hline No & $b$ (in) & $h$ (in) & nb_b_I & nb_b_m & nb_b_r & nb_u_I & nb_u_m & nb_u_r & n_bar_b_l & n_bar_b_m & n_bar_b_r & n_bar_u_l & n_bar_u_m & n_bar_u_r \\
\hline 1 & 16 & 18 & 4 & 4 & 4 & 4 & 4 & 4 & 7 & 7 & 7 & 7 & 7 & 7 \\
\hline 7 & 12 & 22 & 3 & 4 & 2 & 3 & 2 & 2 & 6 & 6 & 6 & 6 & 10 & 8 \\
\hline 10 & 9 & 22 & 2 & 3 & 2 & 2 & 3 & 3 & 7 & 6 & 4 & 5 & 5 & 6 \\
\hline 15 & 10 & 16 & 2 & 2 & 2 & 2 & 2 & 2 & 6 & 6 & 6 & 6 & 6 & 6 \\
\hline 24 & 9 & 16 & 3 & 3 & 2 & 3 & 4 & 4 & 5 & 5 & 5 & 5 & 4 & 4 \\
\hline 30 & 9 & 10 & 2 & 2 & 2 & 2 & 2 & 2 & 4 & 4 & 4 & 4 & 4 & 4 \\
\hline
\end{tabular}

Table 4. Section dimensions, longitudinal reinforcements designed for some elements of the best solution.

Table 5 lists shear reinforcements designed for some elements of the best solution.

Table 5. Shear reinforcements designed for some elements of the best solution. 


\begin{tabular}{|c|c|c|c|c|c|c|c|c|}
\hline No & Av_s_l & Av_s_r & Av_s_min_l & Av_s_min_r & x_.5vc_l & x_5vc_r & x_vc_l & x_vc_r \\
\hline 1 & 0.0133 & 0.0133 & 0.0133 & 0.0133 & 78.72 & 78.72 & 0 & 0 \\
\hline 7 & 0.01 & 0.0165 & 0.01 & 0.01 & 37.2376 & 136.6009 & 0 & 186.2017 \\
\hline 10 & 0.0089 & 0.0169 & 0.0075 & 0.0075 & 60.6602 & 137.5829 & 22.3205 & 176.1657 \\
\hline 15 & 0.0083 & 0.0083 & 0.0083 & 0.0083 & 78.72 & 78.72 & 0 & 0 \\
\hline 24 & 0.015 & 0.0075 & 0.0075 & 0.0075 & 63.6099 & 119.03 & 36.2199 & 147.06 \\
\hline 30 & 0.0075 & 0.0075 & 0.0075 & 0.0075 & 78.72 & 78.72 & 0 & 0 \\
\hline
\end{tabular}

In this table:

- $A v_{-} s_{-}(l / r)$ : Shear reinforcement area in unit length for the left/right half of the elements, $i n^{2} / i n$.

- $A v_{-} s_{-} \min \_(l / r)$ : Minimum permitted shear reinforcement area in unit length for the left/right half of the elements, $i n^{2} / i n$.

- $\quad x_{-} .5 v c_{-}(l / r)$ : Distance between point with shear force of $.5 v c$ ( $v c$ is shear resistance provided by concrete) and point with shear force of zero for the left/right half of the elements, in .

- $\quad x_{-} v c_{-}(l / r)$ : Distance between point with shear force of $v c$ ( $v c$ is shear resistance provided by concrete) and point with shear force of zero for the left/right half of the elements, in .

In this research, design time has been assumed as a determining parameter, here the selection operator with specified conditions and the new operator repairing has been used to accelerate convergence of the program. In fact, the selection used in this research causes fewer violated constraints to get in a population as the generation number grows, and then these selected populations are repaired by using the repairing operator. As a result, design time for the two-bay six-story frame with 240 variables is about 80 min., whereas the program used by Camp, Pezeshk and Hanson (2003) need 13 hours to design the same frame with only 36 variables.

\section{CONCLUSIONS}

In this research, optimal design of reinforced concrete frames regarding cost was considered within the limitations and specifications of the ACI code. To design these frames a GA based optimization program was introduced. This program is shown to be applicable and effective especially for problems with large numbers of constraints. Tournament selection with specified conditions and a new repairing operator was used to decrease the design time. The design time in this research is much shorter than the design time needed for the GA implemented by Camp, Pezeshk and Hanson (2003). Design time for the modified version of GA implemented by the latter researchers was about 9.75 times the design time needed for the GA introduced in this research, while the frame variables used in this research are about 6.67 times the variables used for the frame designed by Camp, Pezeshk and Hanson (2003).

\section{UNIT CONVERSIONS}

1 in. $=25.4 \mathrm{~mm}, \quad 1 \mathrm{kip}=4,450 \mathrm{~N}, \quad 1 \mathrm{k} \mathrm{in.}=113 \mathrm{~N} \mathrm{~mm}, \quad 1 \mathrm{ksi}=6.9 \mathrm{MPa}$

\section{REFERENCES}

A. Kaveh, O. Sabzi, " Optimal design of reinforced concrete frames Using big bang-big crunch algorithm", International Journal of Civil Engineering, (2012), Vol. 10, No. 3, pp.189-200.

AMERICAN CONCRETE INSTITUTE. "Building Code Requirements for Structural Concrete and Commentary-ACI 318r-05". (2005). Farming Hills, MI., USA.

ASHLOCK, D. "Evolutionary Computation for Modeling and Optimization", Springer, New York. (2006).

CAMP, C., PEZESHK, S., "Flexural Design of Reinforced Concrete Frames Using Genetic Algorithm", Journal of Structural Engineering, (2003), Vol. 129, No.1, pp.105-115. 
CHAN, C., WANG, S. M., "Nonlinear Stiffness Design Optimization of Tall Reinforced Concrete Buildings under Service Loads", Journal of Structural Engineering, (2006). Vol. 132, No. 6, pp. 978990.

De JONG, K. FOGEL, L. SCHWEFEL, H. "Handbook of Evolutionary Computation". Oxford University Press. LONDON, (1997).

Mamoun Alqedra, Mohammed Arafa, Mohammed Ismail, "Optimum Cost of Prestressed and Reinforced Concrete Beams using Genetic Algorithm", Journal of Artificial Intelligence, (2011). 4: 76-88.

LEE, C. J, AHN. "Flexural Design of Reinforced Concrete Frames by Genetic Algorithm". Journal of Structural Engineering, (2003). Vol. 129, No. 6, pp. 762-774.

MOHARRAMI, H. GRIERSON, D. E., "Computer-Automated Design of Reinforced Concrete Frames". Journal of Structural Engineering, (1993). Vol. 119, No. 7, pp. 2036-2058.

SARMA, K. C., ADELI, H., "Cost Optimization of Concrete Structures". Journal of Structural Engineering, (1998), Vol. 124, No. 5, pp. 570-578.

Yousif S.T., Najem R.M., "Optimum cost design of reinforced concrete continuous beams using Genetic Algorithms", Int. Journal of Applied Sciences and Engineering Research, (2013). Vol. 2, No. 1, pp. 79-92. 